\title{
Percepção de saúde no Brasil: uma análise das diferenças por sexo dos trabalhadores *
}

\author{
Bruna Naiara de Castro ** \\ Jefferson Andronio Ramundo Staduto ${ }^{* * *}$
}

\section{Resumo}

A saúde afeta diretamente a produtividade e renda dos trabalhadores e, por sua vez, as desigualdades de gênero afetam de forma desproporcional a saúde de ambos os sexos. Nesse sentido, o objetivo central desse trabalho é analisar os fatores que influenciam a percepção de saúde dos trabalhadores do sexo feminino e masculino. A base de dados utilizada foi o suplemento da Pesquisa Nacional de Amostra Domiciliar de 2008. Foram estimados modelos probit em dois estágios para captar as contribuições das características socioeconômicas para a percepção de saúde das pessoas ocupadas por sexo. Os principais resultados mostraram que, em média, as mulheres apresentam menor percepção de boa saúde do que os homens. Portanto, é necessário que as políticas públicas foquem nos determinantes das desigualdades de saúde entre homens e mulheres, tais como a diferença salarial, trabalho precário e a dupla jornada de trabalho. Além disso, são necessárias políticas de saúde que atendam às necessidades especificas de homens e mulheres.

Palavras-chaves: Saúde; Trabalhador; Desigualdade de gênero.

\begin{abstract}
Health perception in Brazil: an analysis of the differences by gender of the workers

Health directly affects workers' productivity and income, and, in turn, gender inequalities disproportionately affect both sexes. This study analyzes the differences between the health of male and female workers. The database used was the 2008 National Household Sample Survey. Probit models in two stages were estimated to obtain the contributions of the socioeconomic characteristics of the working person's health according to gender. The main results showed that, on average, women had a lower perceived health status than men. Therefore, public policies must focus on the determinants of health inequalities between men and women, such as the wage gap, precarious work and working double shifts. In addition, health policies that address the specific needs of men and women are needed.
\end{abstract}

Keywords: Health; Worker; Gender inequality.

JEL I00, I20, I30.

\section{Introdução}

A saúde dos trabalhadores é uma parte do capital humano porque é essencial para aumentar a produtividade e, consequentemente, os rendimentos (Schultz, 1973; Becker, 1994). Um trabalhador fisicamente e mentalmente mais saudável produz mais do que um trabalhador não saudável, e deverá receber maior remuneração. Basov (2002) argumenta que a saúde é

\footnotetext{
${ }^{*}$ Artigo recebido em 10 de julho de 2017 e aprovado em 18 de junho de 2018.

** Professora da União de Ensino Superior de Cafelândia (ÚNICA), Cafelândia, PR, Brasil. E-mail: bn_castro@hotmail.com.

*** Professor da Universidade Estadual do Oeste do Paraná (UNIOESTE), Toledo, PR, Brasil. E-mail: jefferson.staduto@unioeste.br.
} 
considerada o segundo tipo mais importante de capital humano, ficando atrás da educação. Entretanto, as pesquisas referentes à saúde como capital humano ainda não são muito frequentes, principalmente no Brasil, de acordo com Murrugarra e Valdivia (1999) e Soytas e Kose (2014) essa situação ocorre fundamentalmente por conta da falta de base de dados e das dificuldades conceituais. Os trabalhos na literatura nacional de Costa (2008) e Sousa (2010) abordam a relevância da educação para a saúde, entretanto, há outros pontos de vista que merecem ser aprofundados, por exemplo, a diferença de saúde por sexo.

Para Silva e Almeida-Filho (2009) as desigualdades em saúde podem ser interpretadas como resultado do acesso desigual por indivíduos que pertencem ao mesmo grupo social. Já a equidade em saúde pode ser interpretada como o resultado de políticas que atendam às necessidades específicas de indivíduos que não são iguais. $\mathrm{O}$ sexo distingue os diferentes papéis socialmente construídos, normas, comportamentos, atividades e atributos que uma determinada sociedade considera apropriados para homens e mulheres. As desigualdades de gênero afetam de forma desproporcional a saúde das mulheres (Hosseinpoor et al., 2012; Fernandes et al., 2012; Soytas; Kose, 2014).

Proteger a saúde de homens e mulheres não é apenas um direito humano básico, mas, também, crucial para o desenvolvimento econômico da nação. É importante garantir que o sistema de saúde seja sensível às necessidades de homens e mulheres (Hosseinpoor et al., 2012). Compreender a desigualdade de percepção de saúde é importante para a formulação de políticas públicas de saúde e, se o sexo tem influência na percepção de saúde, as políticas de saúde específicas por sexo podem ajudar na redução dessa desigualdade de gênero (Soytas; Kose, 2014).

Neste contexto, o objetivo desta pesquisa consiste em analisar os fatores que influenciam a percepção de saúde de homens e mulheres ocupados em atividades laborais. Além desta introdução, esta pesquisa compreende mais cinco seções. Na primeira, apresentase uma breve abordagem da saúde na literatura. A segunda compreende as diferenças de saúde por sexo dos trabalhadores. Na terceira, apresenta-se a estratégica metodológica e modelo de estimação. A quarta compreende a apresentação dos resultados e discussões. Por fim, na quinta seção apresentam-se as conclusões.

\section{Saúde na teoria econômica: uma breve abordagem}

A saúde aparece como uma variável relevante fundamentalmente em duas abordagens na teoria econômica: bem-estar e capital humano. O item 1.1 apresenta a primeira abordagem e o 1.2 e 1.3 compreende a apresentação da segunda abordagem.

\subsection{Saúde na abordagem de bem-estar}

A definição de bem-estar varia entre campo da ciência e entre pesquisador. Em geral, as definições desenvolvidas pelos psicólogos são mais abrangentes em comparação com os conceitos aplicados por sociólogos e economistas. Os psicólogos consideram o bem-estar 
subjetivo, muitas vezes "bem-estar psicológico" ou "saúde mental”. Na visão dos psicólogos, os componentes do bem-estar psicológico que se relacionam com "sentir-se bem" incluem emoções de contentamento, felicidade, mas também interesse e engajamento, confiança e relações sociais. Essa definição está mais relacionada à qualidade de vida (Fischer, 2009).

O bem-estar subjetivo é considerado um conceito complexo que integra uma dimensão cognitiva e uma dimensão efetiva, englobando outros conceitos e dimensões, como a qualidade de vida, emoções negativas e emoções positivas. Portanto, o bem-estar subjetivo consiste em um juízo avaliativo, normalmente exposto em termos de satisfação e felicidade do indivíduo com a sua vida (Diener et al., 2003; Galinha; Ribeiro, 2005).

Os sociólogos e os economistas definem o bem-estar subjetivo de forma mais restrita, excluindo algumas facetas incluídas pelos psicólogos ou da abordagem de qualidade de vida. Por exemplo, o funcionamento físico e mental não seriam considerados componentes do bemestar subjetivo, mas sim visto como suas condições, além disso, também, são excluídos os aspectos relacionados aos significados da vida (Fischer, 2009).

Nessa linha de pensamento Stiglitz et al. (2009) argumentam que é necessário usar uma abordagem multidimensional para definir o bem-estar subjetivo. As dimensões chave que devem ser levadas em conta são: i. padrões de vida materiais (renda, consumo e riqueza); ii. saúde; iii. educação; iv. atividades pessoais, incluindo trabalho; v. voz política e governança; vi. conexões e relacionamentos sociais; vii. ambiente (condições presentes e futuras); viii. insegurança, de natureza econômica e física. Todas essas dimensões contribuem para o bemestar das pessoas e, no entanto, muitas delas são perdidas por abordagens baseadas em recursos disponíveis dos indivíduos, ou seja, o bem-estar unidimensional relacionado à renda e ao consumo.

O bem-estar subjetivo pode ser sintetizado por variáveis latentes, tais como satisfação de vida e experiências hedônicas (Luechinger, 2007). Segundo Stiglitz et al. (2009) essas variáveis fornecem informações incompletas sobre o bem-estar subjetivo.

\subsection{Saúde como capital humano}

Schultz (1973) argumenta que o capital humano não é composto apenas por educação formal e treinamento mas, também, pela saúde dos trabalhadores, isto é, todo o gasto que afeta a expectativa de vida, a capacidade de resistência, o vigor físico e a vitalidade de um povo. $\mathrm{O}$ capital humano é de extrema importância para determinar o crescimento e desenvolvimento econômico da economia. Alguns economistas empenharam-se em determinar os efeitos dos progressos verificados no campo da saúde por meio da mensuração da saúde que incrementam a qualidade dos recursos humanos, por exemplo, a alimentação adicional e condições de moradia. Para Becker (1994) um alto nível de saúde da população reduz a taxa de mortalidade e induz um aumento nos investimentos em educação e outros tipos de capital humano, uma vez que a taxa de retorno desses investimentos será maior quanto mais tempo de vida tiver o 
indivíduo. O investimento em capital humano é uma das maneiras mais eficientes de aumentar o nível de renda e de saúde da população mais pobre.

A família é um importante componente na composição do capital humano. A renda da família influencia os ganhos futuros dos filhos. Pais mais educados e com mais cultura formal têm melhores condições de ajudar no desenvolvimento das capacidades, da cultura formal, da educação e das habilidades de seus filhos. De outro lado, os pais que possuem pelo menos o nível básico de instrução, elaboram um planejamento a fim de direcionar os filhos a receber um melhor nível de educação. Trata-se de uma função de utilidade, em que os pais abrem mão do consumo de bens e serviços, porque acreditam no retorno da educação futura dos filhos. Os pais, neste caso, são investidores, já que estão renunciando a alguns gastos, reduzindo seu consumo para gastar com habilidades, saúde, aprendizado e motivação para seus filhos (Becker, 1962).

Além disso, a saúde tem impacto sobre a oferta de trabalho, mais especificamente na escolha setorial, na decisão de trabalhar e no número de horas a ser ofertado. Considerando as duas últimas questões, o resultado de uma saúde precária sobre a oferta de trabalho é ambíguo, dependendo da combinação de três efeitos. O primeiro efeito é o da "dotação", pelo qual o indivíduo doente dispõe de menos tempo para realizar suas atividades normais, inclusive para o trabalho. O segundo efeito é o da "substituição", assim, se uma saúde precária corresponde a uma taxa de salários mais baixa, o trabalhador decide reduzir a sua oferta de trabalho, já que o trabalho gera uma desutilidade ao indivíduo, portanto, há um efeito substituição entre trabalho e lazer. Por fim, o terceiro efeito é o da "renda", que faz o doente trabalhar mais para compensar os menores rendimentos por hora. Se o efeito renda for grande o suficiente para compensar o efeito dotação mais o efeito substituição, uma saúde precária resulta em maior oferta de trabalho. Caso contrário, um indivíduo doente tende a trabalhar menos tempo do que uma pessoa saudável (Strauss, 1998; Alves; Andrade, 2003).

O stress no local de trabalho desempenha papel importante nas diferenças de saúde. Existe um círculo virtuoso entre saúde e produtividade, pois melhorias nas condições de trabalho levarão a uma força de trabalho mais saudável, o que levará a uma melhor produtividade e, consequentemente, para a oportunidade de criar um ambiente de trabalho ainda mais saudável e mais produtivo (Wilkinson; Marmot, 2003).

Uma grande proporção da literatura converge para a teoria do capital humano para analisar a relação entre saúde e educação. Desta forma, este trabalho se alinha à abordagem preponderante na literatura, a qual, normalmente, parte do precursor do tema, Michael Grossman (1972) que desenvolveu um modelo teórico de demanda por saúde. Na próxima subseção apresentam-se algumas contribuições do autor.

\subsection{A relação entre saúde e educação}

Grossman (2000) encontrou evidências de que a educação é a variável explicativa mais

importante nos resultados de boa saúde. Sendo que educação e saúde têm impacto significativo 
sobre a produtividade dos trabalhadores e sobre o bem-estar individual. Fuchs (2004) também acredita que a educação é a variável mais importante para a saúde, e contra-argumenta os autores que creditam a renda como a principal variável, pois eles argumentam que a educação está servindo como um proxy para a renda de longo prazo. No entanto, para Fuchs (2004, p. 647) "in cross-section studies, income has sharply diminishing effects on health as income rises, but the apparent effect of additional years of schooling is undiminished at all levels".

A correlação positiva entre saúde e escolaridade pode ser explicada de três maneiras. Na primeira argumenta-se que existe uma relação casual no sentido da educação para saúde. A segunda sustenta que a direção da causalidade vai da saúde para educação. Já a terceira argumenta que existe uma "terceira variável" que afeta a saúde e educação na mesma direção, tornando o modelo estimado uma regressão espúria. Estas explicações não são mutuamente exclusivas e podem ser usadas para racionalizar uma correlação observada entre quaisquer duas variáveis (Grossman, 2000).

A causalidade da educação para a saúde ocorre quando as pessoas mais educadas são mais eficientes na produção de saúde, uma vez que conhecem as informações sobre os verdadeiros efeitos dos insumos na saúde. Por exemplo, os indivíduos mais instruídos podem ter mais conhecimento sobre os efeitos nocivos de uma dieta não saudável. Alternativamente, a direção da causalidade positiva pode ocorrer da saúde para a educação, estudantes mais saudáveis podem ser mais eficientes no aprendizado escolar. Além disso, esse caminho causal pode ter efeitos duradouros se a saúde passada foi um insumo no atual estado de saúde. Assim, mesmo para as pessoas não estudantes, uma relação positiva entre saúde e escolaridade pode refletir causalidade reversa na ausência de controles para saúde passada. A explicação da "terceira variável" pode ser relevante quando uma grande variação inexplicada na saúde permanece após o controle da escolaridade e outros determinantes e, também, se os fatores omitidos que afetam a saúde estiverem correlacionados com a escolaridade (Grossman, 2000).

\section{Diferenças de percepção de saúde entre homens e mulheres}

O papel da mulher na sociedade já esteve assentado na reprodução biológica, com ênfase na maternidade e nos afazeres domésticos. Já o papel do homem é definido como o exercício do poder econômico na esfera pública. Essa dicotomia entre os papéis masculino e feminino, embora esteja traçada ao longo dos séculos, e consagrada numa relativa divisão sexual do trabalho, tem mudado bastante na história recente da humanidade (Kon, 2002; Melo et al., 2005).

O sexo ganhou importância na análise da equidade e cuidados com a saúde por chamar a atenção para um tipo específico de inequidade, referente à natureza social, econômica e cultural de cada sexo. É necessário identificar as semelhanças e as diferenças nas necessidades de saúde entre homens e mulheres, bem como identificar e analisar os obstáculos que, com base no sexo, os impedem de permanecer ou estar saudáveis. As atitudes dos homens referentes à saúde têm relação com as suas vivências, o que é resultado dos padrões de masculinidade. A 
negação de fraqueza e a rejeição da ajuda são práticas hegemônicas da masculinidade. A relação entre a masculinidade e os cuidados com a saúde tem sido, sobretudo, descrita em relação às doenças características/especificas masculinas (câncer de próstata e testicular ou doença cardiovascular) (Fernandes et al., 2012).

Para Doyal (2001) as diferenças biológicas entre homens e mulheres foram durante muito tempo consideradas como um dos principais fatores que inviabilizava a comparação entre a saúde de homens e mulheres. A organização dos cuidados e dos serviços de saúde deveria estar de acordo com as necessidades claramente distintas. Esta diferença relativa ao sexo não se limita à saúde reprodutiva, mas, também, incluíam diferenças genéticas, hormonais e metabólicas consideradas determinantes dos padrões de mortalidade e morbidade. Ferreira e Santana (2003) argumentam que além das diferenças biológicas, outros aspectos englobam a problemática da desigualdade de saúde. O fato de as mulheres apresentarem percepções inferiores de saúde, independente de outras variáveis, estaria diretamente relacionado às desigualdades de gênero reproduzidas na sociedade. Esta constatação sugere o efeito independente do sexo sobre o estado de saúde. Nesse sentido, Prus e Gee (2003) argumentam que os diferenciais em termos de participação na força de trabalho, independência financeira e responsabilidades domésticas contribuem para as diferenças de percepção de saúde de sexo ao longo da vida.

De acordo com Soytas e Kose (2014) existem duas hipóteses principais sobre mecanismos sociais que poderiam explicar as diferenças de sexo nos resultados de saúde. i) a hipótese de diferencial de exposição sugere que as mulheres relatam níveis de saúde mais baixos do que os homens, devido às maiores exigências e obrigações em seus papéis sociais e níveis mais baixos de recursos para ajudá-las a lidar com essas condições. Isto implica que equivalentes papéis sociais e recursos iguais devem eliminar as diferenças de sexo nos resultados de saúde. ii) por outro lado, a hipótese de diferencial de vulnerabilidade faz referência à maior capacidade de resposta das mulheres aos eventos da vida e tensões contínuas que são experimentadas igualmente por ambos os sexos. Ainda segundo os autores, nenhuma hipótese encontra pleno apoio empírico nos dados.

Estas relações desiguais atravessam todas as dimensões da vida social, possuem dinâmica própria independente de outros processos sociais, e são marcadas pelo antagonismo, isto é, a relação hierárquica dos homens sobre as mulheres. As mulheres, consequentemente, acabam inseridas em espaços desvalorizados socialmente, ficando restritas à ascensão social e econômica. Em média, as mulheres ocupam cargos menos importantes e, consequentemente, recebem menos por hora trabalhada, possuem pouca autonomia no desempenho das suas atividades e estão mais sujeitas ao trabalho precário. Essas características do trabalho feminino podem levar ao desgaste físico, psicológico e, assim, interferir na forma como as mulheres avaliam sua saúde (Barata, 2009; Soytas; Kose, 2014; Singh et al., 2013). A defesa da equidade na saúde decorre do reconhecimento de que algumas das diferenças existentes são expressões das desigualdades sociais. A principal razão para estudos de saúde sensíveis ao gênero é 
Percepção de saúde no Brasil: uma análise das diferenças por sexo dos trabalhadores

providenciar informações para definir planos de políticas e ações que possam reduzir essas inequidades e melhorar os resultados em termos de saúde (Fernandes et al., 2012).

\section{Estratégica metodológica}

De acordo com Costa (2008) o modelo de Grossman fornece a base teórica para um amplo número de modelos empíricos. Na literatura sobre o tema, um dos principais questionamentos tem sido se o efeito da educação na equação de saúde é espúrio e, portanto, determinado pela "terceira variável". Isto acontece quando não são utilizadas proxies adequadas para as variáveis omitidas. Duas estratégias têm sido adotadas para controlar o viés gerado pela "terceira variável". A primeira consiste em criar proxies para as variáveis omitidas e para o estado de saúde inicial e inseri-las diretamente na equação de saúde. A segunda se refere a tratar a educação na equação de saúde como uma variável endógena, e estimá-la em dois estágios. Esta pesquisa adotou a segunda estratégia de acordo com as evidências empíricas e conceituais de Grossman (2000) da educação como variável relevante na explicação da saúde. Portanto, foi aplicado um modelo probit pelo método dos dois estágios para a estimação dos parâmetros, assim como nos trabalhos realizados por Costa (2008), Sousa (2010), Brunello et al., (2011), em razão da vantagem de controlar a educação como variável endógena da saúde.

O modelo econométrico é composto pelo seguinte sistema de equações:

$$
\begin{aligned}
& Y_{i} \text { Saúde }=\beta_{0}+\beta_{1} Y_{i} \text { Educação }+\sum \beta_{j} X_{i j} \text { Saúde }+e_{i} \\
& Y_{i} E d u c a c ̧ a ̃ o=\alpha_{0}+\sum \alpha_{j} X_{i j} E d u c a c ̧ a ̃ o+\mu_{i}
\end{aligned}
$$

A variável endógena e $Y_{i} E d u c a c ̧ a ̃ o$ foi representada por uma grandeza contínua, ou seja, os anos de estudos completos da população ocupada. A variável $Y_{i}$ Saúde foi representada por uma binária, indicando a probabilidade de o ocupado se declarar com boa saúde (1 para boa e 0 caso contrário). Por sua vez, $\sum \alpha_{j} X_{i j} E d u c a c ̧ a ̃ o$ e $\sum \beta_{j} X_{i j}$ Saúde são os fatores exógenos que influenciam a educação e a percepção de saúde, respectivamente, $e_{\mathrm{i}} \mathrm{e} u_{\mathrm{i}}$ são os erros aleatórios não explicados pelo modelo.

De acordo com Pindyck e Rubinfeld (2004) quando uma das variáveis é endógena, a equação deve ser estimada por um método em dois estágios. Este método permite eliminar a inconsistência devida à correlação entre a variável independente endógena e o termo de erro do modelo. No primeiro estágio, obtém-se a variável instrumental fortemente relacionada à variável endógena independente, mas não correlacionada ao termo de erro. Esta variável foi prevista por uma equação reduzida, na qual a variável endógena foi ajustada em função de todas as variáveis exógenas do problema conforme equação (2).

$$
Y_{i} E d u c a c ̧ a ̃ o=\pi_{0}+\sum \pi_{j} X_{i j} E d u c a c ̧ a ̃ o+\sum \pi_{j} X_{i j} \text { Saúde }+\mu_{i}
$$

A ausência de variável independente endógena na equação reduzida (2) garantiria, segundo os pressupostos do modelo clássico de regressão linear, estimativas consistentes e não tendenciosas dos parâmetros da equação. O próximo passo do método de dois estágios é substituir a variável independente endógena do sistema de equações estruturais (1) pela respectiva variável instrumental prevista pela equação (2). Esta substituição é apresentada na 
equação (3). O uso de variável instrumental na equação (3) garantiria estimativas consistentes para os parâmetros na presença de correlação entre o termo de erro e a variável explanatória. Assim, a variável instrumental seria um bom preditor para a variável endógena original, uma vez que todos os fatores explanatórios estão na equação reduzida (2) (Greene, 2002; Pindyck; Rubinfeld, 2004).

$$
Y_{i} \text { Saúde }=\beta_{0}+\beta_{1} \hat{Y}_{i} \text { Educação }+\sum \beta_{j} X_{i j} \text { Saúde }+e_{i}
$$

A equação com variável dependente binária $\left(Y_{i}^{\text {Saúde }}\right)$ foi ajustada por uma função de probabilidade normal acumulada, isto é, um modelo probit, utilizando o método de máxima verossimilhança. A probabilidade condicional estimada por este modelo refere-se à probabilidade do indivíduo declarar-se saudável. Assim, os parâmetros $\left(\beta_{\mathrm{j}}\right)$, na interpretação do modelo probit, significam a contribuição individual das variáveis na probabilidade de a variável dependente ocorrer. Os valores negativos expressam uma queda na probabilidade, enquanto os positivos significam um aumento na probabilidade (Greene, 2002; Wooldrige, 2008).

Com o objetivo de verificar se a variável Educação era endógena na equação de Saúde, foi realizado o Teste de Endogeneidade de Hausman. De acordo com Pindyck e Rubinfeld (2004); Wooldrige (2008), esse teste consiste em estimar a equação reduzida (2), na qual a educação está em função de todas as variáveis exógenas do problema. Obter os resíduos e adicioná-los como um regressor na equação (1) que será repetida abaixo já com os resíduos $\left(\delta_{1} \hat{\mu}_{i}\right)$ adicionados como equação (1.1).

$$
\begin{aligned}
& Y_{i} \text { Saúde }=\beta_{0}+\beta_{1} Y_{i} \text { Educação }+\sum \beta_{j} X_{i j} \text { Saúde }+\delta_{1} \hat{\mu}_{i}+e_{i} \\
& \mathrm{H}_{0:} \delta_{1}=0 \text { (hipótese de exogeneidade) } \\
& \mathrm{H}_{\mathrm{A}:} \delta_{1} \neq 0 \text { (hipótese de endogeneidade) }
\end{aligned}
$$

Usando a estatística $t$, rejeitando $\mathrm{H}_{0}$ a um pequeno nível de significância, conclui-se que a variável Educação era endógena, isto significa que os resíduos da equação (2) e os resíduos da equação (1) estavam correlacionados.

\subsection{Base de dados e variáveis}

As análises foram feitas com base nas informações do suplemento de saúde da Pesquisa Nacional por Amostra de Domicílio - PNAD - de 2008 - Instituto Brasileiro de Geografia e Estatísticas - IBGE. Considerou-se os ocupados com 10 até 65 anos de idade que tinham trabalho remunerado na semana de referência ou que exerciam trabalho não remunerado, incluindo as atividades relacionadas ao autoconsumo e construção para o próprio uso. Trata-se do último suplemento sobre saúde da PNAD, o anterior é de 2003. Os dados desse suplemento são os mais recentes disponíveis para obtermos as respostas para o problema de pesquisa. Nesse estudo não foi considerada a Pesquisa Nacional de Saúde - PNS - de 2013, apesar de mais recente, pois não continha todas as variáveis que o modelo estimado precisaria para ser bem especificado. No caso dos suplementos de saúde, por exemplo, é possível controlar os dados sobre condições de saúde individual em relação variáveis de posição na ocupação, ramo de 
atividade, entre outros, para análises específicas sobre mercado de trabalho (Maia; Rodrigues, 2010).

A variável de interesse principal refere-se à percepção de saúde do indivíduo. A pergunta que se faz é: "De um modo geral, considera seu próprio estado de saúde como? "; com cinco categorias de respostas: "muito bom", "bom", "regular", "ruim" e "muito ruim". Essa variável foi dicotomizada, dividindo os indivíduos como saudáveis àqueles que reportaram seu estado de saúde como "muito bom" ou "bom" e não saudáveis àqueles que responderam como "regular", "ruim" ou "muito ruim" (Maia; Rodrigues, 2010).

A definição de saúde da Organização Mundial de Saúde (OMS): saúde é a ausência de enfermidade e a presença de bem-estar físico, mental e social (WHO, 1946). "Em seu sentido mais abrangente, saúde é resultante das condições de alimentação, habitação, educação, renda, meio-ambiente, trabalho, transporte, emprego, lazer, liberdade, acesso e posse da terra e acesso a serviços de saúde" (Brasil, 1986, p. 12). Scliar (2007) estudou a história do conceito de saúde e, para o autor, este conceito reflete a conjuntura social, econômica, política e cultural, portanto, saúde não representa a mesma coisa para todas as pessoas. Dependerá da época, do lugar, da classe social, dos valores individuais, das concepções científicas, religiosas e filosóficas.

Segundo Benjamins et al. (2004), Maia e Rodrigues (2010) o indicador de percepção de saúde auto declarada feita pelos institutos de pesquisa tem a vantagem de refletir não somente a saúde física mas, também, a emocional, que pode estar associada ao grau de satisfação do indivíduo com sua vida pessoal e/ou ambiente social em que está inserido, o que afeta sua percepção de saúde. Além, disso tem a vantagem de ser uma medida ampla do estado de saúde, que engloba todas as morbidades e, também, tem relação com a mortalidade da população. Esta medida tem sido uma das mais utilizadas na literatura, uma vez que o custo associado a esse tipo de questão nas pesquisas domiciliares de grande cobertura populacional é menor. Entre os estudos que utilizaram a percepção de saúde estão Dachs (2002); Maia e Rodrigues (2010); Hosseinpoor et al. (2012); Cruzeiro e Veríssimo (2013); Singh et al. (2013) e Soytas e Kose (2014).

Entretanto, deve-se considerar alguns problemas relacionados à percepção de saúde nas pesquisas domiciliares. Como se trata de uma medida subjetiva, a percepção de saúde pode ser diferente entre distintos grupos sociais, étnicos ou culturais. Adultos e idosos, por exemplo, podem considerar mais natural declararem um bom estado de saúde mesmo em piores condições relativas às dos mais jovens. Outro problema se refere ao informante das respostas. Como não é possível garantir a presença de todos os moradores do domicílio no momento da entrevista, a avaliação daqueles ausentes acaba sendo subjetivamente feita por parte de outra pessoa (Jürgues, 2006; Maia; Rodrigues, 2010).

No Quadro 1 estão as 17 variáveis e respectivas referências, que foram usadas para estimar as equações (1), (2) e (3). Na equação (1) e (3) foram incluídas as 16 primeiras variáveis; e na equação (2) foram incluídas somente as seguintes variáveis: a) Idade; b) Pobre; c) Branca; d) Urbano; e) Gerentes, sendo essa última a variável instrumental. Tanto as estatísticas descritivas como os resultados das estimativas levam em consideração o fator de expansão da PNAD, assim os resultados apresentados são representativos para a população. 
Quadro 1

Resumo das variáveis utilizadas nas pesquisas de saúde como variável dependente

\begin{tabular}{|c|c|c|}
\hline $\begin{array}{c}\text { Variáveis } \\
\text { Explicativas }\end{array}$ & Tipo e Descrição & Referências \\
\hline Educação & $\begin{array}{l}\text { Uma variável contínua que considera os anos completos de } \\
\text { estudo do ocupado; }\end{array}$ & $\begin{array}{l}\text { Dachs, 2002; Singh, et al., } \\
\text { 2013; Singh et al., } 2013\end{array}$ \\
\hline Branca & $\begin{array}{l}\text { Uma variável binária que assume } 1 \text { quando ocupado se } \\
\text { declarou da cor branca e zero quando o ocupado se declarou } \\
\text { da cor não branca; }\end{array}$ & $\begin{array}{l}\text { Dachs, 2002; Maia e } \\
\text { Rodrigues, 2010; Soytas e } \\
\text { kose, } 2014\end{array}$ \\
\hline $\begin{array}{l}\text { Formal e Conta } \\
\text { Própria }\end{array}$ & $\begin{array}{l}\text { Duas variáveis binárias, a primeira assume } 1 \text { quando o } \\
\text { ocupado trabalhava no mercado de trabalho formal e zero } \\
\text { caso contrário. Já a segunda variável assume } 1 \text { quando o } \\
\text { ocupado trabalhava por conta própria e zero caso contrário, } \\
\text { tendo escolhido como referência os trabalhadores sem } \\
\text { carteira assinada. }\end{array}$ & Giatti e Barreto, 2006 \\
\hline Idade & $\begin{array}{l}\text { Uma variável contínua que considera os anos de Idade do } \\
\text { ocupado; }\end{array}$ & $\begin{array}{l}\text { Dachs, 2002; Singh et al., } \\
\text { 2013; Soytas e Kose, } 2014\end{array}$ \\
\hline $\begin{array}{l}\text { Norte, Sul, } \\
\text { Centro-Oeste e } \\
\text { Nordeste }\end{array}$ & $\begin{array}{l}\text { Quatro variáveis binárias para distinguir cinco regiões, a } \\
\text { região o Sudeste foi } a \text { referência; }\end{array}$ & $\begin{array}{l}\text { Kassouf, 1997; Maia e } \\
\text { Rodrigues, 2010; Singh et } \\
\text { al., } 2013\end{array}$ \\
\hline $\begin{array}{l}\text { Afazeres } \\
\text { Domésticos }\end{array}$ & $\begin{array}{l}\text { Uma variável contínua que considera as horas dedicadas a } \\
\text { afazeres domésticos. }\end{array}$ & $\begin{array}{l}\text { Barata, 2009; Fernandes et } \\
\text { al., } 2012\end{array}$ \\
\hline Chefe & $\begin{array}{l}\text { Uma variável binária que assume } 1 \text { quando o ocupado se } \\
\text { declarou chefe de família e zero caso contrário; }\end{array}$ & Kassouf, 1997. \\
\hline $\begin{array}{l}\text { Horas } 35 \text { e } \\
\text { Horas } 45\end{array}$ & $\begin{array}{l}\text { Duas variáveis binárias para jornada de trabalho. A primeira } \\
\text { assume } 1 \text { quando o ocupado trabalhava até } 35 \text { horas por } \\
\text { semana. Já a segunda variável assume } 1 \text { quando o ocupado } \\
\text { trabalhava mais que } 45 \text { horas por semana, tendo escolhido } \\
\text { como referência a jornada de trabalho maior que } 35 \text { horas e } \\
\text { menor que } 45 \text { horas, ou seja, de } 36 \text { a } 44 \text { horas por semana. }\end{array}$ & $\begin{array}{l}\text { Kassouf, 1997; Maia e } \\
\text { Rodrigues, } 2010\end{array}$ \\
\hline Declarante & $\begin{array}{l}\text { Uma variável binária que assume } 1 \text { quando o próprio } \\
\text { entrevistado declarou sua percepção de saúde e zero quando } \\
\text { declarado por outra pessoa do domicílio; }\end{array}$ & $\begin{array}{l}\text { Dachs, 2002; Maia e } \\
\text { Rodrigues, } 2010\end{array}$ \\
\hline Pobre ${ }^{(1)}$ & $\begin{array}{l}\text { Uma variável binária que assume } 1 \text { quando o ocupado recebia } \\
\text { renda domiciliar per capita até } 1 / 2 \text { salário mínimo e zero } \\
\text { quando o ocupado recebia mais que } 1 / 2 \text { salário mínimo. }\end{array}$ & $\begin{array}{l}\text { Kassouf, 1997; Maia e } \\
\text { Rodrigues, 2010; Singh et } \\
\text { al., } 2013\end{array}$ \\
\hline Urbano & $\begin{array}{l}\text { Uma variável binária que assume } 1 \text { quando o ocupado residia } \\
\text { na zona urbana e zero quando o ocupado residia na zona rural. }\end{array}$ & $\begin{array}{l}\text { Dachs, 2002; Maia e } \\
\text { Rodrigues, 2010; Singh et } \\
\text { al., } 2013\end{array}$ \\
\hline $\begin{array}{l}\text { Consulta } \\
\text { médica }\end{array}$ & $\begin{array}{l}\text { Uma variável binária que assume } 1 \text { quando o ocupado } \\
\text { consultou o médico nos últimos doze meses e zero caso } \\
\text { contrário. }\end{array}$ & Mendes e Sala, 2011 \\
\hline Gerente & $\begin{array}{l}\text { Uma variável binária que assume } 1 \text { quando os indivíduos } \\
\text { trabalhavam nas ocupações de gerentes, dirigentes e } \\
\text { dirigentes do poder público e zero caso contrário }\end{array}$ & (SOUSA, 2010) \\
\hline
\end{tabular}

(1) Nos trabalhos citados a variável se referia a renda ou ao salário. Nesta pesquisa, a variável pobre foi usada com o objetivo de captar o impacto da pobreza na percepção de saúde dos ocupados.

Fonte: Elaboração própria, com base na literatura citada. 


\subsection{Variável instrumental}

Gerente é a variável instrumental da equação (2). Segundo Sousa (2010), essa variável estaria muito mais correlacionada com a educação do que com a saúde dos trabalhadores, portanto, seria um bom instrumento. Outros estudos sobre o tema selecionaram diferentes variáveis como instrumento, tais como background familiar, por exemplo, a escolaridade dos pais, renda per capita média estadual e gasto per capita com educação estadual (Sander 1995; Leigh e Dhir 1997). No entanto, segundo Sousa (2010) estas variáveis estariam correlacionadas com a saúde dos indivíduos e, portanto, não seriam bons instrumentos. Outros autores, tais como Lleras-Muney (2002), Arendt (2005) utilizaram variáveis institucionais, por exemplo, leis que aumentaram a escolaridade mínima.

O uso de variáveis instrumentais deve satisfazer dois requisitos: o instrumento deve ser não-correlacionado com o erro, e correlacionado com a variável explicativa endógena. Se os instrumentos utilizados forem fracos, dois problemas ocorrem na estimativa em dois estágios: O primeiro diz respeito à questão do viés, embora o método seja consistente, as estimativas são sempre enviesadas para pequenas amostras. No segundo, o erro padrão estimado se torna muito pequeno. Assim, o intervalo de confiança padrão não é fidedigno, porque, além do estimador ser enviesado, o intervalo de confiança se torna pequeno. Diante disso, o procedimento de teste de hipótese na estimativa em dois estágios se fragiliza na ocorrência de instrumentos fracos (Andrews et al. 2006; Finlay; Magnusson, 2009; Sachsida et al., 2011).

$\mathrm{Na}$ literatura existem vários testes para examinar a hipótese de instrumentos fracos, por exemplo, o teste de Stock e Yogo (2005) têm como hipótese nula que o conjunto de instrumentos utilizados são fracos. A abordagem mais recente ao problema de instrumentos fracos e único regressor endógeno é o teste da razão de verossimilhança condicional proposto por Moreira (2003) e aperfeiçoado por Andrews et al. (2006) e implementado pela rotina Stata de Finlay e Magnusson (2009) para testes de hipóteses. A abordagem condicional é empregada para encontrar funções de valor crítico para os testes de razão e taxa de verossimilhança que produzem probabilidades de rejeição mais precisa, não importa quão fracos são os instrumentos. Segundo Andrews et al. (2006), Finlay e Magnusson (2009) e Sachsida et al. (2011), o teste da razão de verossimilhança condicional supera as distorções encontradas nos testes convencionais ajustando os valores críticos do teste de hipótese de acordo com cada amostra, de modo que o intervalo de confiança corrigido gere um nível de significância mais preciso. Assim, optou-se por aplicar o teste da razão de verossimilhança condicional proposto por Moreira (2003) com objetivo de verificar se o instrumento utilizado é fraco ou não. 


\section{Resultados e discussões}

No Brasil, o expressivo percentual de ocupados que declararam, em 2008, percepção de saúde boa e muito boa $(78,1 \%)$ esconde diferenças relevantes entre trabalhadores do sexo feminino e masculino (Tabela 1). Entre esses grupos, destaca-se a diferença de quase 5 pontos percentuais (p.p.) na percepção de saúde. Os homens correspondem a 56,2\% da população ocupada e $80,1 \%$ consideram-se saudáveis. Para as mulheres estes percentuais equivalem a $43,8 \%$ e 75,5\%, respectivamente, cujos resultados estão de acordo com os encontrados tanto em pesquisas nacionais como internacionais. Para Soytas e Kose (2014) não há um consenso sobre os mecanismos que levam às diferenças de sexo nos resultados de saúde. A principal explicação para a pior percepção de saúde das mulheres está relacionada às diferenças biológicas e sociais, que provocam uma dupla jornada de trabalho, além da menor participação no mercado de trabalho.

Tabela 1

Distribuição dos ocupados por sexo e estado declarado de saúde - Brasil (2008)

\begin{tabular}{c|c|c|c}
\hline Sexo & $\begin{array}{c}\text { Número de } \\
\text { Ocupados }\end{array}$ & Ocupados (\%) & Saudáveis (\%) \\
\hline Homens & 53.105 .005 & 56,2 & 80,1 \\
\hline Mulheres & 41.367 .173 & 43,8 & 75,5 \\
\hline Total & 94.472 .178 & 100 & 78,1 \\
\hline
\end{tabular}

Fonte: Elaboração própria a partir dos microdados da PNAD/IBGE (suplemento de saúde).

Na contramão dos resultados de percepção de saúde, a longevidade aumentou substancialmente mais para as mulheres do que para os homens nos países desenvolvidos, especialmente a partir do século XX. Um padrão semelhante parece estar ocorrendo em países de baixa renda. A vantagem da longevidade para as mulheres é um desenvolvimento recente, pois antes do século XX a longevidade feminina era raramente superior à masculina (Schultz, 1993).

Apesar de a longevidade das mulheres ser maior que a dos homens, elas reportam percepção de boa saúde com menos frequência. Existem três hipóteses para essa mudança de diferenças de sexo na longevidade, são que (i) as causas de morte mudaram, provavelmente devido à introdução de tratamentos médicos para doenças infecciosas e parasitárias; (ii) a dieta ou a assistência médica das mulheres em comparação com a dos homens foi melhorada; e (iii) as diferenças de ocupações mudaram, assim como os riscos da saúde associados a ambos os sexos (Schultz, 1993). Além disso, existe a problemática da violência vivida pelos homens nos espaços públicos, ressaltando as mortes por causas externas, tais como as que ocorrem no trânsito e os homicídios (Pinheiro; Couto, 2012).

De acordo com Pinheiro et al. (2002) e Gorman e Read (2006) esta contradição se reduz quando se leva em consideração diferenças no padrão de doenças, em diferentes faixas 
etárias. Os homens sofrem mais doenças crônicas de maior mortalidade, tais como: doença isquêmica do coração, aterosclerose, enfisema, câncer, acidente vascular cerebral, cirrose, problemas de rins. As mulheres apresentam, mais frequentemente, doenças de curta duração, doenças agudas e transitórias, tais como infecções das vias respiratórias superiores, gastroenterite e doenças infecciosas de curta duração, além de doenças crônicas de menor mortalidade, tais como artrite, sinusite crônica, problemas digestivos, anemia, problemas de tireoide ou vesícula, enxaqueca, colite e eczema. Estas doenças apresentam baixa letalidade, apesar de serem, em muitos casos, incapacitantes e gerarem uma grande demanda por serviços de saúde.

A variável de percepção de saúde está sujeita a erros de medida, com destaque para o viés em relação às informações relatadas pelos sexos. Os homens são menos propensos a reportar problemas de saúde do que as mulheres. De modo geral, as mulheres demandam mais serviços de saúde em relação aos homens, e este diferencial pode ser explicado pelo perfil de necessidade entre os sexos, uma vez que as mulheres necessitam de cuidados com a gravidez e o parto. Outro fator é o maior interesse das mulheres pelos cuidados com a saúde (PINHEIRO et al., 2002).

Na Tabela 2 apresenta-se dados referentes à procura por consulta médica dos ocupados nos últimos doze meses. Observou-se que 79,7\% das mulheres responderam ter consultado o médico no período, ao passo que entre os homens, apenas $54,5 \%$ consultaram o médico nos últimos 12 meses. Mendes e Sala (2011) relatam que quando excluídas as internações por gravídez e parto, a proporção de internações masculinas é um pouco superior à feminina, tendo sido de 50,8\% em 2000 e 50,5\% em 2010.

Tabela 2

Distribuição dos ocupados por sexo e a procura por consulta ao médico nos últimos 12 meses - Brasil (2008).

\begin{tabular}{c|c|c|c}
\hline Gênero & Número de Ocupados & Ocupados $(\%)$ & Consultou Médico (\%) \\
\hline Homens & 53.105 .005 & 56,2 & 54,5 \\
\hline Mulheres & 41.367 .173 & 43,8 & 79,7 \\
\hline Total & 94.472 .178 & 100 & 65,5 \\
\hline
\end{tabular}

Fonte: Elaboração própria a partir dos microdados da PNAD/IBGE (suplemento de saúde).

Entre os fatores que aumentam o risco de doenças entre as mulheres, estão a obesidade, o stress, as pressões ligadas ao papel social exercido pelas mulheres. Já entre os homens verifica-se a maior ocorrência de fumo, a ingestão de álcool e desvantagens em situações relacionadas ao trabalho, o que acarretam aumento de riscos de problemas a longo prazo (Pinheiro et al., 2002). Com relação ao total de ocupados, as mulheres possuiam mais doenças que os homens em 2008, exceto para as doenças de tuberculose e cirrose (Tabela 3). As mulheres se declararam mais saudáveis que os homens, quando se considera os ocupados que possuíam as doenças de artrite ou reumatismo, câncer, depressão, insuficiência renal crônica, tuberculose e cirrose. 
Tabela 3

Distribuição dos ocupados por sexo e a ocorrência de doenças constatadas por um médico ou profissional da saúde, além do estado declarado de saúde - Brasil (2008)

\begin{tabular}{l|c|c|c|l|c|c|c}
\hline \multicolumn{1}{c}{ Doenças } & Ocupados & $(\%)$ & $\begin{array}{c}\text { Saudávei } \\
\text { s }(\%)\end{array}$ & \multicolumn{1}{c|}{ Doenças } & Ocupados & $(\%)$ & $\begin{array}{c}\text { Saudáveis } \\
(\%)\end{array}$ \\
\hline Coluna ou Costas & 7.208 .195 & 13,6 & 51,5 & Coluna ou Costas & 7.105 .472 & 17,2 & 49,1 \\
\hline $\begin{array}{l}\text { Artrite ou } \\
\text { Reumatismo }\end{array}$ & 1.603 .626 & 3,0 & 35,8 & $\begin{array}{l}\text { Artrite ou } \\
\text { Reumatismo }\end{array}$ & 2.684 .231 & 6,5 & 36,4 \\
\hline Câncer & 157.929 & 0,3 & 37,1 & Câncer & 216.703 & 0,5 & 45,9 \\
\hline Diabetes & 1.404 .687 & 2,6 & 38,1 & Diabetes & 1.180 .208 & 2,8 & 31,7 \\
\hline Bronquite ou Asma & 1.616 .433 & 3,0 & 61,1 & Bronquite ou Asma & 1.827 .094 & 4,4 & 56,9 \\
\hline Hipertensão & 5.960 .681 & 11,2 & 49,5 & Hipertensão & 6.100 .427 & 14,7 & 45,1 \\
\hline Coração & 1.331 .605 & 2,5 & 32,0 & Coração & 1.320 .632 & 3,2 & 32,0 \\
\hline $\begin{array}{l}\text { Insuficiência renal } \\
\text { crônica }\end{array}$ & 627.957 & 1,2 & 35,9 & $\begin{array}{l}\text { Insuficiência renal } \\
\text { crônica }\end{array}$ & 630.756 & 1,5 & 36,2 \\
\hline Depressão & 1.129 .549 & 2,1 & 35,0 & Depressão & 2.695 .141 & 6,5 & 39,3 \\
\hline Tuberculose & 81.598 & 0,1 & 40,2 & Tuberculose & 49.665 & 0,1 & 51,9 \\
\hline $\begin{array}{l}\text { Tendinite ou } \\
\text { Tenossinovite }\end{array}$ & 930.578 & 1,7 & 57,6 & $\begin{array}{l}\text { Tendinite ou } \\
\text { Tenossinovite }\end{array}$ & 2.109 .968 & 5,1 & 55,2 \\
\hline Cirrose & 96.341 & 0,2 & 33,8 & Cirrose & 32.512 & 0,1 & 46,4 \\
\hline
\end{tabular}

Fonte: Elaboração própria a partir dos microdados da PNAD/IBGE (suplemento de saúde).

Soytas e Kose (2014) verificaram que para mulheres nos Estados Unidos e Turquia havia maior prevalência de doenças crônicas e, por vezes, incapacitantes. No Brasil, segundo a Tabela 4 este comportamento também ocorre, o percentual de incapacidade das mulheres equivale a $8,8 \%$, enquanto dos homens corresponde a $6,5 \%$, apesar de elas apresentarem maior percentual de incapacidade, elas se avaliaram tão saudáveis quanto os homens nesta situação.

Tabela 4

Distribuição dos ocupados por sexo, incapacidade de realizar atividades habituais e estado declarado de saúde Brasil (2008)

\begin{tabular}{c|c|c|c|c|c|c|c}
\hline \multicolumn{4}{c|}{ Homem } & \multicolumn{4}{c}{ Mulher } \\
\hline Incapacidade & $\begin{array}{c}\text { Número de } \\
\text { Ocupados }\end{array}$ & $(\%)$ & Saudáveis (\%) & Incapacidade & $\begin{array}{c}\text { Número de } \\
\text { Ocupados }\end{array}$ & $(\%)$ & $\begin{array}{c}\text { Saudáveis } \\
(\%)\end{array}$ \\
\hline Sim & 3.444 .781 & 6,5 & 38,4 & Sim & 3.666 .550 & 8,8 & 38,3 \\
\hline Não & 49.660 .224 & 93,5 & 83,0 & Não & 37.700 .623 & 91,1 & 79,1 \\
\hline Total & 53.105 .005 & 100 & 80,1 & Total & 41.367 .173 & 100 & 75,5 \\
\hline
\end{tabular}

Fonte: Elaboração própria a partir dos microdados da PNAD/IBGE (suplemento de saúde). 
A crescente inserção das mulheres no mercado de trabalho nas últimas décadas apresentou efeito protetor em relação ao seu estado de saúde, uma vez que tal fato proporcionou o aumento da renda e maior independência feminina. O principal impacto da melhoria no estado de saúde ocorreu sobre a saúde mental, mas, quando comparadas aos homens, a situação de saúde mental das mulheres ainda se mostrava inferior (Barata, 2009).

A Tabela 5 apresenta os resultados de saúde dos ocupados quanto à prática de atividades domésticas. Observa-se que, em média, as mulheres gastam 19 horas com afazeres domésticos por semana e 74,5\% delas se declararam saudáveis. Referente aos homens estes valores correspondem a 4 horas gastas com afazeres domésticos e 79,6\% deles se declararam saudáveis. Um resultado relevante aparece quando se analisa os dados dos ocupados que não praticam atividades domésticas: o percentual de mulheres nesta categoria que se declararam mais saudáveis foi ligeiramente maior do que os homens, estes percentuais equivalem a 83,3\% e $80,6 \%$, respectivamente. Esta inversão nos resultados de saúde reflete como a percepção de saúde das mulheres melhorava quando elas não enfrentavam a dupla jornada de trabalho. Apesar da maior inserção da mulher no mercado de trabalho, as atividades domésticas ainda são, na maioria das vezes, executadas por elas.

\section{Tabela 5}

Distribuição dos ocupados por sexo, horas dedicadas em afazeres domésticos na semana e estado declarado de saúde - Brasil (2008).

\begin{tabular}{|c|c|c|c|c|c|c|c|}
\hline \multicolumn{4}{|c|}{ Homem } & \multicolumn{4}{|c|}{ Mulher } \\
\hline $\begin{array}{c}\text { Média de Horas } \\
\text { Gastas com Afazeres } \\
\text { Domésticos }\end{array}$ & Ocupados & $(\%)$ & $\begin{array}{c}\text { Saudáveis } \\
(\%)\end{array}$ & $\begin{array}{c}\text { Média de Horas } \\
\text { Gastas com Afazeres } \\
\text { Domésticos }\end{array}$ & Ocupados & $(\%)$ & $\begin{array}{c}\text { Saudáveis } \\
(\%)\end{array}$ \\
\hline 4 & 24.803 .837 & 47 & 79,6 & 19 & 36.730 .677 & 89 & 74,5 \\
\hline 0 & 28.301 .168 & 53 & 80,6 & 0 & 4.636 .496 & 11 & 83,3 \\
\hline Total & 53.105 .005 & 100 & 80,1 & Total & 41.367 .173 & 100 & 75,5 \\
\hline
\end{tabular}

Fonte: Elaboração própria a partir dos microdados da PNAD/IBGE (suplemento de saúde).

A ocupação do trabalhador tem reflexo importante no estado de saúde dos indivíduos. Ocupações menos qualificadas e de baixos salários normalmente apresentam características nocivas à saúde física e mental dos trabalhadores (Mendes, 1988; Neri et al., 2005). Giatti e Barreto (2006) encontraram evidências de que o trabalho informal está associado a uma pior condição de saúde entre adultos brasileiros independentemente das características sociodemográficas. A Tabela 6 apresenta os resultados de percepção de saúde por situação da ocupação e sexo, sendo que as mulheres se declararam menos saudáveis do que os homens nas três situações de ocupação: mercado formal, informal e por conta própria. Destaca-se que a maior diferença ocorre no mercado de trabalho informal, onde 79,6\% dos homens se declararam saudáveis, enquanto para mulheres este percentual equivale 70,3\%, uma diferença de cerca 9 p.p. 
Tabela 6

Distribuição dos ocupados por sexo, situação na ocupação e estado declarado de saúde - Brasil (2008).

\begin{tabular}{l|c|c|c|l|c|c|c}
\hline \multicolumn{5}{c|}{ Homem } & \multicolumn{3}{c}{ Mulher } \\
\hline $\begin{array}{l}\text { Situação na } \\
\text { Ocupação }\end{array}$ & Ocupados & $(\%)$ & $\begin{array}{c}\text { Saudáveis } \\
(\%)\end{array}$ & $\begin{array}{l}\text { Situação na } \\
\text { Ocupação }\end{array}$ & Ocupados & $(\%)$ & $\begin{array}{c}\text { Saudáveis } \\
(\%)\end{array}$ \\
\hline Formal & 26.854 .704 & 51 & 84,3 & Formal & 18.785 .942 & 45 & 82,3 \\
\hline Conta Própria & 11.703 .304 & 22 & 71,2 & Conta Própria & 5.958 .487 & 14 & 68,5 \\
\hline Informal & 14.546 .997 & 27 & 79,6 & Informal & 16.622 .744 & 40 & 70,3 \\
\hline Total & 53.105 .005 & 100 & 80,1 & Total & 41.367 .173 & 100 & 75,5 \\
\hline
\end{tabular}

Fonte: Elaboração própria a partir dos microdados da PNAD/IBGE (suplemento de saúde).

Vintém et al. (2008) avaliaram as desigualdades de saúde por sexo em Portugal, e seus resultados apontaram para o fato de que as classes sociais mais desfavorecidas possuem uma tendência de declarar negativamente seu estado de saúde e de descreverem um sentimento positivo de bem-estar menos frequente, além disso, declararam que vão com mais frequência às consultas médicas. Segundo Fernandes et al. (2012) entre os determinantes de saúde, as condições socioeconômicas são as que melhor explicam as diferenças de morbidade e mortalidade no final da vida.

Os dados para o Brasil apresentados na Tabela 7 confirmam a relação positiva entre saúde e salário em quase todas as faixas de salário, pois à medida que aumentava a faixa de renda, também crescia a percepção de saúde para os homens e mulheres. Para homens decrescia a partir da faixa >3,5 a 4 salários mínimos e para mulheres a partir da faixa $>4$ a 4,5 salários mínimos.

Tabela 7

Distribuição dos ocupados por sexo, salário principal e estado declarado de saúde - Brasil (2008)

\begin{tabular}{|c|c|c|c|c|c|c|c|}
\hline \multicolumn{4}{|c|}{ Homem } & \multicolumn{4}{|c|}{ Mulher } \\
\hline $\begin{array}{c}\text { Salário } \\
\text { Principal }\end{array}$ & Ocupados & $(\%)$ & $\begin{array}{c}\text { Saudáveis } \\
(\%)\end{array}$ & $\begin{array}{c}\text { Renda } \\
\text { domiciliar } \\
\text { per capita }\end{array}$ & Ocupados & $(\%)$ & $\begin{array}{c}\text { Saudáveis } \\
(\%)\end{array}$ \\
\hline $0 \mathrm{a}^{1} / 2$ & 6.945 .219 & 13,1 & 73,1 & 0 a $1 / 2$ & 9.509 .373 & 23,0 & 62,8 \\
\hline$>1 / 2$ a 1 & 9.189 .923 & 17,3 & 75,3 & $>1 / 2$ a 1 & 8.287 .788 & 20,0 & 72,5 \\
\hline$>1$ a 1,5 & 9.389 .532 & 17,7 & 78,9 & $>1$ a 1,5 & 7.790 .300 & 18,8 & 79,4 \\
\hline$>1,5$ a 2 & 7.279 .199 & 13,7 & 82,0 & $>1,5$ a 2 & 3.776 .805 & 9,1 & 83,1 \\
\hline$>2$ a 2,5 & 4.446 .720 & 8,4 & 84,5 & $>2$ a 2,5 & 2.043 .350 & 4,9 & 85,9 \\
\hline$>2,5$ a 3 & 2.716 .848 & 5,1 & 84,4 & $>2,5$ a 3 & 1.112 .874 & 2,7 & 86,8 \\
\hline$>3$ a 3,5 & 1.125 .097 & 2,1 & 86,4 & $>3$ a 3,5 & 525.961 & 1,3 & 88,1 \\
\hline$>3,5$ a 4 & 1.935 .305 & 3,6 & 85,1 & $>3,5$ a 4 & 877.266 & 2,1 & 89,8 \\
\hline$>4$ a 4,5 & 2.346 .788 & 4,4 & 84,1 & $>4$ a 4,5 & 1.045 .972 & 2,5 & 88,5 \\
\hline$>5$ & 7.730 .374 & 14,5 & 84,5 & $>5$ & 6.397 .484 & 15,5 & 78,5 \\
\hline Total & 53.105 .005 & 100 & 80,1 & Total & 41.367 .173 & 100 & 75,5 \\
\hline
\end{tabular}

Fonte: Elaboração própria a partir dos microdados da PNAD/IBGE (suplemento de saúde). 
As mulheres se declararam menos saudáveis que os homens apenas nas duas faixas de salário mais baixas ( 0 a $1 \frac{1}{2}$ salários mínimos e $>1 / 2$ a 1 salários mínimos) e, também, na faixa de renda mais alta (> 5 salários mínimos), nestas faixas, somado o percentual de mulheres ocupadas, representava 58,5\%. Esta concentração de ocupadas que declararam percepção inferior de saúde contribui para que, em média, a percepção de saúde feminina seja menor que a masculina. Em todas as outras faixas de renda as mulheres se declararam mais saudáveis que os homens.

De acordo com Ross e Wu (1995), o efeito da escolaridade é relevante na percepção de saúde, em razão de dois aspectos principais. O primeiro refere-se ao fato do nível de instrução ser a principal causa das desigualdades sociais em saúde porque se reflete nos rendimentos dos indivíduos. Em segundo lugar, indivíduos com maiores níveis de escolaridade são mais propensos a adotar hábitos de vida saudáveis, tais como a prática de atividade física, a manutenção de peso adequado, o consumo moderado de álcool e o hábito de não fumar. A Tabela 8 apresenta os resultados de percepção de saúde segundo os anos de estudos e o sexo dos ocupados. Independentemente dos anos de estudo, as mulheres se declararam menos saudáveis que os homens mas, para ambos os sexos, conforme aumentam os anos de estudo, aumentavam os percentuais de saudáveis. No estrato de 12 a 15 anos de estudo, a percepção de saúde entre homens e mulheres é praticamente igual. A diferença de percepção de saúde entre homens e mulheres foi maior para as pessoas com baixa escolaridade e praticamente desapareceu no último estrato de escolaridade, podendo estar relacionada ao esgotamento dos efeitos da educação. Por exemplo, é provável que alunos do ensino médio aprendam algo na escola que faça com que eles adotem hábitos de vida mais saudáveis do que os alunos que abandonaram a escola no ensino fundamental, no entanto, chegará um ponto em que anos adicionais de educação não terão uma contribuição marginal tão grande na saúde (FUCHS, 2004).

Tabela 8

Distribuição dos ocupados por sexo, anos de estudos e estado declarado de saúde - Brasil (2008)

\begin{tabular}{c|c|c|c|c|c|c|c}
\hline \multicolumn{4}{c|}{ Homem } & \multicolumn{3}{c}{ Mulher } \\
\hline $\begin{array}{c}\text { Anos de } \\
\text { estudos }\end{array}$ & Ocupados & $(\%)$ & $\begin{array}{c}\text { Saudáveis } \\
(\%)\end{array}$ & $\begin{array}{c}\text { Anos de } \\
\text { estudos }\end{array}$ & Ocupados & $(\%)$ & $\begin{array}{c}\text { Saudáveis } \\
(\%)\end{array}$ \\
\hline Sem instrução & 4.808 .072 & 9,0 & 62,5 & Sem instrução & 2.719 .721 & 6,6 & 52,9 \\
\hline 1 a 4 & 10.942 .429 & 20,6 & 69,4 & 1 a 4 & 6.818 .782 & 16,5 & 58,5 \\
\hline 5 a 8 & 14.101 .892 & 26,5 & 80,7 & 5 a 8 & 9.141 .351 & 22,1 & 71,6 \\
\hline 9 a 11 & 16.821 .410 & 31,7 & 87,5 & 9 a 11 & 14.947 .877 & 36,1 & 82,6 \\
\hline 12 a 15 & 6.431 .202 & 12,1 & 90,8 & 12 a 15 & 7.739 .442 & 18,7 & 89,1 \\
\hline Total & 53.105 .005 & 100 & 80,1 & Total & 41.367 .173 & 100 & 75,5 \\
\hline
\end{tabular}

Fonte: Elaboração própria a partir dos microdados da PNAD/IBGE (suplemento de saúde).

A jornada de trabalho curta, quando não é voluntária, pode estar associada a situações precárias de empregabilidade, tal como condição insalubre, além de maior incidência de 
problemas relacionados ao consumo de álcool e à depressão. De forma oposta, jornadas excessivas de trabalho estão associadas à incidência de acidentes de trabalho, fadiga, problemas cardiovasculares, entre outros. Portanto, pressupõe-se uma relação na forma de "U" invertido entre saúde e jornada de trabalho (Maia; Rodrigues, 2010). No Brasil, segundo a Tabela 9, observa-se exatamente este comportamento: o percentual de ocupados que se declararam saudáveis aumenta da jornada de trabalho de até 35 horas por semana para a jornada de 36 a 44 horas por semana, mas o percentual de saudáveis diminui para a jornada de trabalho acima de 45 horas por semana. As mulheres se declararam menos saudáveis que os homens em todas as jornadas de trabalho, sendo que na jornada de 36 a 44 horas a diferença ficou em cerca de apenas $1 \%$.

Tabela 9

Distribuição dos ocupados por sexo, jornada de trabalho e estado declarado de saúde - Brasil (2008)

\begin{tabular}{c|c|c|c|c|c|c|c}
\hline \multicolumn{3}{c|}{ Homem } & \multicolumn{4}{c}{ Mulher } \\
\hline $\begin{array}{c}\text { Jornada de } \\
\text { Trabalho }\end{array}$ & Ocupados & $(\%)$ & $\begin{array}{c}\text { Saudáveis } \\
(\%)\end{array}$ & $\begin{array}{c}\text { Jornada de } \\
\text { Trabalho }\end{array}$ & Ocupados & $(\%)$ & $\begin{array}{c}\text { Saudáveis } \\
(\%)\end{array}$ \\
\hline$<=35$ horas & 8.427 .252 & 15,9 & 77,4 & $<=35$ horas & 14.344 .907 & 34,7 & 70,1 \\
\hline$>=36$ e $<=44$ horas & 22.756 .697 & 42,8 & 82,6 & $\begin{array}{c}>=36 \mathrm{e}<=44 \\
\text { horas }\end{array}$ & 14.383 .518 & 34,7 & 81,5 \\
\hline$>=45$ horas & 21.921 .056 & 41,2 & 78,6 & $>=45$ horas & 12.638 .748 & 30,5 & 74,7 \\
\hline Total & 53.105 .005 & 100 & 80,1 & Total & 41.367 .173 & 100 & 75,5 \\
\hline
\end{tabular}

Fonte: Elaboração própria a partir dos microdados da PNAD/IBGE (suplemento de saúde).

De acordo com Grossman (1972) a taxa de depreciação da saúde cresce com os anos de idade dos indivíduos. Os resultados de percepção de saúde relacionando a idade e sexo (Tabela 10) mostraram que a saúde e a idade apresentaram relação negativa pois, conforme aumenta a idade, se reduzem os percentuais de indivíduos saudáveis. Referente ao sexo, as mulheres se declararam menos saudáveis que os homens em todas as faixas etárias.

Tabela 10

Distribuição dos ocupados por sexo, idade e estado declarado de saúde - Brasil (2008)

\begin{tabular}{c|c|c|c|c|c|c|c}
\hline \multicolumn{4}{c|}{ Homem } & \multicolumn{4}{c}{ Mulher } \\
\hline Idade & Ocupados & $(\%)$ & $\begin{array}{c}\text { Saudáveis } \\
(\%)\end{array}$ & Idade & Ocupados & $(\%)$ & $\begin{array}{c}\text { Saudáveis } \\
(\%)\end{array}$ \\
\hline 10 a 14 & 1.036 .431 & 1,9 & 90,0 & 10 a 14 & 523.547 & 1,3 & 89,4 \\
\hline 15 a 17 & 2.245 .925 & 4,2 & 91,4 & 15 a 17 & 1.323 .442 & 3,2 & 86,0 \\
\hline 18 a 25 & 10.996 .375 & 20,7 & 90,2 & 18 a 25 & 8.306 .800 & 20,1 & 86,0 \\
\hline 26 a 35 & 13.648 .321 & 25,7 & 86,1 & 26 a 35 & 11.189 .408 & 27,0 & 81,8 \\
\hline 36 a 45 & 11.855 .605 & 22,3 & 78,2 & 36 a 45 & 9.992 .209 & 24,1 & 73,2 \\
\hline 46 a 55 & 8.813 .508 & 16,6 & 68,2 & 46 a 55 & 6.995 .858 & 16,9 & 62,5 \\
\hline 56 a 65 & 4.508 .840 & 8,5 & 57,7 & 56 a 65 & 3.035 .909 & 7,3 & 53,8 \\
\hline Total & 53.105 .005 & 100 & 80,12 & Total & 41.367 .173 & 100 & 75,48 \\
\hline
\end{tabular}

Fonte: Elaboração própria a partir dos microdados da PNAD/IBGE (suplemento de saúde). 
Os determinantes sociais têm papel decisivo na qualidade de vida, no bem-estar e na saúde de homens e mulheres que envelhecem. Ao longo do processo de envelhecimento acentuam-se as diferenças, as vantagens e desvantagens decorrentes de status socioeconômicos diferentes. A trajetória de vida possui altos e baixos resultantes de realizações pessoais e/ou de frustações. A partir de certa idade, as condições sociais, econômicas e culturais adquiridas condicionam ou contribuem para práticas de cuidados de saúde e o nível de saúde que o indivíduo irá usufruir na velhice. Assim, o indivíduo em idade avançada depende do capital de saúde construído ao longo de uma vida (Fernandes et al., 2012).

\subsection{Resultados do modelo econométrico}

Nesta subseção apresentam-se os resultados do Teste de Endogeneidade de Hausman, Teste de Razão de Verossimilhança Condicional (CLR) e os Efeitos marginais do modelo Probit em dois estágios. Os resultados do modelo probit para estimar a equação (3) foram apresentados em 4 modelos com o objetivo de verificar se a variável Educação permanece endógena e significativa depois de incorporadas algumas variáveis de controle. Além disso, os modelos foram estimados por sexo separadamente com o intuito de verificar e comparar como as variáveis socioeconômicas impactavam na saúde de homens e mulheres. O Teste de Endogeneidade de Hausman foi realizado para verificar se a variável Educação era endógena. Como foi observado na seção anterior, se a variável resíduo adicionada na equação (1.1) fosse estatisticamente significativa, a variável Educação era endógena. Assim, com base na Tabela 11, verifica-se que o teste de Hausman tanto para as mulheres como para os homens em todos os modelos rejeita $\mathrm{H}_{0}$ e, portanto, a variável Educação era endógena.

A Tabela 11 relata os coeficientes da Educação na regressão probit em dois estágios e os números entre colchetes correspondem aos intervalos de confiança padrão e intervalo de confiança robusto para instrumentos fracos com base na abordagem da razão de verossimilhança condicional (CLR) para homens e para mulheres. Avaliar a sensibilidade da inferência para a fraqueza do instrumento consiste em comparar o intervalo de confiança padrão e o intervalo de confiança robusto para instrumentos fracos. Os limites de confiança robustos do instrumento fraco CLR resultaram em inferência semelhante para o coeficiente da Educação com os limites de confiança padrão em todos os modelos e para ambos os sexos. Este resultado sugere que é improvável que o problema de instrumento fraco, variável Gerente, tenha substancialmente influenciado os efeitos da Educação no modelo probit em dois estágios. O coeficiente CLR rejeita $\mathrm{H}_{0}$ de que o coeficiente da variável endógena (educação) é igual a zero em todos os modelos e para ambos os sexos. 
Tabela 11

Resultados do Teste de Hausman e Teste de Razão de Verossimilhança Condicional (CLR) para homens e para mulheres- Brasil (2008)

\begin{tabular}{|c|c|c|c|c|}
\hline \multicolumn{5}{|c|}{ Mulher } \\
\hline & Modelo 1 & Modelo 2 & Modelo 3 & Modelo 4 \\
\hline Educação & $0,12 * * *$ & $0,12 * * *$ & $0,13 * * *$ & $0,14 * * *$ \\
\hline \multirow[t]{2}{*}{ Int. Conf. Padrão } & {$[0,12-0,13]$} & {$[0,12-0,13]$} & {$[0,10-0,16]$} & {$[0,11-0,17]$} \\
\hline & $(0,00)$ & $(0,02)$ & $(0,01)$ & $(0,01)$ \\
\hline Int. Conf. CLR & {$[0,11-0,13]$} & {$[0,11-0,13]$} & {$[0,10-0,16]$} & {$[0,11-0,17]$} \\
\hline CLR & $755,49 * * *$ & $650,63 * * *$ & $63,62 * * *$ & $70,50 * * *$ \\
\hline \multirow[t]{2}{*}{ Hausman } & $-0,126^{* * *}$ & $-0,126^{* * *}$ & $-0,088 * * *$ & $-0,097 * * *$ \\
\hline & $(0,008)$ & $(0,008)$ & $(0,017)$ & $(0,018)$ \\
\hline \multicolumn{5}{|c|}{ Homem } \\
\hline & Modelo 1 & Modelo 2 & Modelo 3 & Modelo 4 \\
\hline Educação & $0,09 * * *$ & $0,09 * * *$ & $0,09 * * *$ & $0,10 * * *$ \\
\hline \multirow[t]{2}{*}{ Int. Conf. Padrão } & {$[0,08-0,10]$} & {$[0,08-0,10]$} & {$[0,06-0,10]$} & {$[0,07-0,11]$} \\
\hline & $(0,00)$ & $(0,06)$ & $(0,01)$ & $(0,01)$ \\
\hline Int. Conf. CLR & {$[0,08-0,09]$} & {$[0,08-0,09]$} & {$[0,07-0,11]$} & {$[0,08-0,12]$} \\
\hline CLR & $591,76 * * *$ & $546,22 * * *$ & $68,27 * * *$ & $80,08 * * *$ \\
\hline \multirow[t]{2}{*}{ Hausman } & $-0,068 * * *$ & $-0,068 * * *$ & $-0,037 * * *$ & $-0,045^{* * *}$ \\
\hline & $(0,006)$ & $(0,006)$ & $(0,012)$ & $(0,012)$ \\
\hline
\end{tabular}

Fonte: Elaboração própria a partir dos microdados da PNAD/IBGE (suplemento de saúde).

Nota: erro-padrão robusto entre parênteses. *** Denota significância ao nível de $1 \%$; ** Denota significância ao nível de 5\%, * Denota significância ao nível de $10 \%$.

Os Efeitos Marginais do modelo Probit estimado em dois estágios para mulheres e para homens são apresentados nas Tabelas 12 e 13, respectivamente. Pode-se observar, com base no Modelo 4, que cada ano adicional de estudo das mulheres aumentava a probabilidade delas se declararem saudáveis em aproximadamente 3,7 pontos percentuais. Para os homens, este percentual correspondia a 2,2 pontos percentuais. Portanto, a educação tinha maior impacto sobre a percepção de saúde das mulheres do que dos homens. Fuchs (2004) também encontrou forte correlação entre educação e saúde nos Estados Unidos.

Quando considerada a incidência de pobreza, o fato de as mulheres encontrarem-se nesta condição não afetava a percepção de saúde delas, uma vez que a variável não foi estatisticamente significativa. Já para homens, se eles possuíam renda domiciliar menor que $1 / 2$ salário mínimo, então a probabilidade deles se declararem saudáveis diminuía cerca de 2,4 p.p. (Modelo 4). Para as mulheres, o retorno marginal da escolaridade, ou seja, da informação, é mais importante, elas sabem que devem fazer determinado exame de rotina, por exemplo, o exame de câncer de colo do útero ou a mamografia, e de certa forma estão habituadas a irem 
ao consultório médico. Assim, para as mulheres, o efeito da educação estaria mitigando o efeito da pobreza. Já os homens, em média, têm maior resistência a exames relacionados à saúde do homem, por exemplo, o exame de câncer de próstata. Então, a percepção de saúde dos homens pode estar mais relacionada à condição socioeconômica e não ao acesso ao conhecimento. Nesse sentido, Kassouf (1997) verificou a insignificância do salário sobre a percepção de saúde das mulheres.

A saúde diminui com a Idade e o sinal negativo da variável confirma esta relação. No modelo 4, para as mulheres, a cada ano a mais de idade, a probabilidade das mulheres se declararem saudáveis diminuía em torno de 0,3 p.p. Para homens, este percentual correspondia a 0,5 p.p. Soytas e Kose (2014) em um estudo sobre a Turquia e Estados Unidos, também constataram que conforme a idade aumenta, menor é a probabilidade das mulheres se declararem saudáveis.

Se os ocupados consultaram médico nos últimos doze meses, a probabilidade das mulheres se declararem saudáveis diminuía em 13,5 p.p. Para os homens, a probabilidade diminuía em 14,5 p.p. Esta relação negativa entre a percepção de saúde e a consulta médica faz sentido, uma vez que, por meio da consulta médica, os problemas de saúde podem ser identificados, além disso, as pessoas em média tendem a procurar cuidado médico quando já estão doentes e não por prevenção.

De acordo com o Modelo 4, para mulheres, a variável Horas35 (jornada de trabalho curta) apresentou um efeito marginal de - 0,019 ; ou seja, se as mulheres possuíam uma jornada de trabalho menor que 35 horas semanais, a probabilidade delas se declararem saudáveis diminuía em 1,9 p.p. Para homens, também, a probabilidade diminuía em, aproximadamente, 2,3 p.p. Foi adicionado ao modelo uma variável para captar a jornada de trabalho excessiva, isto é, a variável Horas45 se as mulheres trabalhavam mais de 45 horas por semana, a probabilidade delas se declararem saudáveis diminuía em 1,2 p.p. Já para homens, a probabilidade diminuía em 1,4 p.p.

Entre as mulheres que residiam na zona Urbana a probabilidade delas se declararem saudáveis diminuía cerca de 3,9 p.p. e, também, para os homens nestas condições a probabilidade diminuía em 2,7 p.p. Contrariando a expectativa, a variável apresentou sinal negativo para os ambos sexos. Desta forma, sugerindo que as características socioeconômicas dos indivíduos residentes na zona urbana não estavam favorecendo para que eles se declarassem mais saudáveis do que os residentes em áreas rurais. Neste sentindo, Dachs (2002) também encontrou para o Brasil relação positiva entre percepção de saúde e a zona de residência rural. A base de dados utilizada pelo autor foi o suplemento da PNAD de 2003.

No Modelo 4, quando se considera a situação na ocupação, se as mulheres estavam inseridas no mercado formal de trabalho, a probabilidade de elas se declararem saudáveis 
diminuía em torno de 3,0 p.p. Com relação aos homens inseridos no mercado formal, a probabilidade deles se declararem saudáveis aumentava em 1,9 p.p. Se as mulheres trabalhavam por conta própria, a probabilidade delas se declararem saudáveis diminuía em 2,0 p.p. Já para os homens, a probabilidade diminuía em cerca de 0,7 p.p. O trabalho formal tende a estar associado às jornadas de 8 horas diárias, as quais penalizam mais as mulheres, pois a grande maioria tem uma segunda e extensa jornada de trabalho que são os afazeres domésticos.

A variável Declarante foi adicionada ao modelo para controlar o viés associado às respostas sobre a percepção de saúde. Se os homens responderam à pesquisa a respeito da própria saúde, o efeito marginal foi de -0,019. Isto corresponde uma queda na probabilidade deles se declararem saudáveis de 1,9 p.p. (Modelo 4). Para as mulheres, esta variável não foi estatisticamente significativa.

Apesar da literatura apontar para os possíveis problemas de saúde associados à dupla jornada de trabalho feminino (PRUS e GEE, 2003; MELO et al., 2005; SOYTAS e KOSE, 2014), a variável Afazeres Domésticos não foi estatisticamente significativa tanto de homens como de mulheres. Além disso, a variável Chefe não foi significativa para explicar a percepção de saúde para ambos os sexos.

No Modelo 4, a variável Branca torna-se não significativa com a introdução das variáveis de localização regional. Portanto, essa última estimativa mostra que o local de residência é mais importante para explicar a variabilidade da saúde de homens e mulheres do que a cor, quando são incorporadas todas as variáveis independentes do modelo proposto pelo estudo. Segundo Travassos et al. (2006) e Stopa et al. (2017), por exemplo, as pessoas residentes nas regiões Sul e Sudeste apresentaram maiores chances de uso de serviços de saúde público ${ }^{1}$ que residentes nas demais regiões. Por sua vez, o uso do sistema de saúde está associado à sua distribuição geográfica e oferta.

Maia e Rodrigues (2010), no estudo dos ocupados agrícolas e não agrícolas, destacaram o papel relevante das diferenças regionais no estado de saúde. Assim, de acordo com o Modelo 4, quando as mulheres moravam na região Norte, a probabilidade delas se declararem saudáveis diminuía cerca de 8,2 p.p. Quando residiam no Nordeste diminuía 5,7 p.p. Já quando residiam no Sul e no Centro Oeste diminuía 3,2 p.p. e 5,1 p.p., respectivamente. Estes valores para homens foram 7,0 p.p. para o Norte; 3,8 p.p. para o Nordeste; 3,5 p.p. para o Sul e 3,8 p.p. para o Centro Oeste. Percebe-se que as mulheres estão em desvantagem em todas as regiões exceto no Sul em relação à região mais rica do país, o Sudeste.

(1) O Sistema Único de Saúde (SUS) 
Percepção de saúde no Brasil: uma análise das diferenças por sexo dos trabalhadores

Tabela 12

Efeitos marginais da estimação do modelo probit em dois estágios para mulheres, com a educação como endógena - Brasil (2008)

\begin{tabular}{|c|c|c|c|c|}
\hline \multicolumn{5}{|c|}{ Mulheres } \\
\hline Variáveis & Modelo 1 & Modelo 2 & Modelo 3 & Modelo 4 \\
\hline \multirow{2}{*}{ Educação } & $0,034 * * *$ & $0,033 * * *$ & $0,036 * * *$ & $0,037 * * *$ \\
\hline & $(0,001)$ & $(0,001)$ & $(0,004)$ & $(0,003)$ \\
\hline \multirow{2}{*}{ Pobre } & $-0,007$ & $-0,006$ & $-0,003$ & 0,012 \\
\hline & $(0,006)$ & $(0,006)$ & $(0,011)$ & $(0,011)$ \\
\hline \multirow{2}{*}{ Idade } & $-0,004 * * *$ & $-0,004 * * *$ & $-0,003 * * *$ & $-0,003 * * *$ \\
\hline & $(0,000)$ & $(0,000)$ & $(0,000)$ & $(0,000)$ \\
\hline \multirow[b]{2}{*}{ Consultou médico } & $-0,134 * * *$ & $-0,134 * * *$ & $-0,133 * * *$ & $-0,135 * * *$ \\
\hline & $(0,004)$ & $(0,004)$ & $(0,004)$ & $(0,004)$ \\
\hline \multirow{2}{*}{ Horas 35} & - & $-0,019 * * *$ & $-0,023 * * *$ & $-0,019 * * *$ \\
\hline & & $(0,004)$ & $(0,004)$ & $(0,004)$ \\
\hline \multirow{2}{*}{ Horas 45} & - & $-0,017 * * *$ & $-0,014 * * *$ & $-0,012 * *$ \\
\hline & & $(0,004)$ & $(0,005)$ & $(0,005)$ \\
\hline \multirow[b]{2}{*}{ Urbano } & - & - & $-0,026 * * *$ & $-0,039 * * *$ \\
\hline & & & $(0,009)$ & $(0,009)$ \\
\hline \multirow{2}{*}{ Branca } & - & - & $0,021 * * *$ & 0,009 \\
\hline & & & $(0,006)$ & $(0,006)$ \\
\hline \multirow{2}{*}{ Formal } & - & - & $-0,023 * *$ & $-0,030 * * *$ \\
\hline & & & $(0,010)$ & $(0,010)$ \\
\hline \multirow{2}{*}{ Conta Própria } & - & - & $-0,020 * * *$ & $-0,020 * * *$ \\
\hline & & & $(0,005)$ & $(0,005)$ \\
\hline \multirow{2}{*}{ Declarante } & - & - & $-0,008 * *$ & $-0,006$ \\
\hline & & & $(0,004)$ & $(0,004)$ \\
\hline \multirow{2}{*}{ Chefe } & - & - & $-0,003$ & $-0,002$ \\
\hline & & & $(0,003)$ & $(0,003)$ \\
\hline \multirow{2}{*}{ Afazeres domésticos } & - & - & 0,000 & 0,000 \\
\hline & & & $(0,000)$ & $(0,000)$ \\
\hline \multirow{2}{*}{ Norte } & - & - & - & $-0,082 * * *$ \\
\hline & & & & $(0,005)$ \\
\hline \multirow{2}{*}{ Nordeste } & - & - & - & $-0,057 * * *$ \\
\hline & & & & $(0,004)$ \\
\hline \multirow{2}{*}{ Sul } & - & - & - & $-0,032 * * *$ \\
\hline & & & & $(0,005)$ \\
\hline \multirow{2}{*}{ Centro Oeste } & - & - & - & $-0,051 * * *$ \\
\hline & & & & $(0,005)$ \\
\hline
\end{tabular}

Nota: erro-padrão robusto entre parênteses. $* * *$ Denota significância ao nível de 1\%; ** Denota significância ao nível de 5\%, * Denota significância ao nível de $10 \%$.

Fonte: Elaboração própria a partir dos microdados da PNAD/IBGE (suplemento de saúde). 
Bruna Naiara de Castro, Jefferson Andronio Ramundo Staduto

Tabela 13

Efeitos marginais da estimação do modelo probit em dois estágios para homens, com a educação como endógena - Brasil (2008)

\begin{tabular}{|c|c|c|c|c|}
\hline \multicolumn{5}{|c|}{ Homens } \\
\hline Variáveis & Modelo 1 & Modelo 2 & Modelo 3 & Modelo 4 \\
\hline \multirow[t]{2}{*}{ Educação } & $0,022 * * *$ & $0,022 * * *$ & $0,021 * * *$ & $0,022 * * *$ \\
\hline & $(0,001)$ & $(0,001)$ & $(0,003)$ & $(0,003)$ \\
\hline \multirow[t]{2}{*}{ Pobre } & $-0,037 * * *$ & $-0,037 * * *$ & $-0,034 * * *$ & $-0,024 * * *$ \\
\hline & $(0,005)$ & $(0,005)$ & $(0,008)$ & $(0,007)$ \\
\hline \multirow[t]{2}{*}{ Idade } & $-0,005^{* * *}$ & $-0,005^{* * *}$ & $-0,005^{* * * *}$ & $-0,005 * * *$ \\
\hline & $(0,000)$ & $(0,000)$ & $(0,000)$ & $(0,000)$ \\
\hline \multirow[t]{2}{*}{ Consultou médico } & $-0,140 * * *$ & $-0,140 * * *$ & $-0,143 * * *$ & $-0,145 * * *$ \\
\hline & $(0,003)$ & $(0,003)$ & $(0,003)$ & $(0,003)$ \\
\hline \multirow[t]{2}{*}{ Horas 35} & - & $-0,032 * * *$ & $-0,026 * * *$ & $-0,023 * * *$ \\
\hline & & $(0,004)$ & $(0,004)$ & $(0,004)$ \\
\hline \multirow[t]{2}{*}{ Horas 45} & - & $-0,017 * * *$ & $-0,015 * * *$ & $-0,014 * * *$ \\
\hline & & $(0,003)$ & $(0,003)$ & $(0,003)$ \\
\hline \multirow[t]{2}{*}{ Urbano } & - & - & $-0,016 * *$ & $-0,027 * *$ \\
\hline & & & $(0,007)$ & $(0,007)$ \\
\hline \multirow[t]{2}{*}{ Branca } & - & - & $0,014 * * *$ & 0,006 \\
\hline & & & $(0,005)$ & $(0,005)$ \\
\hline \multirow[t]{2}{*}{ Formal } & - & - & $0,026 * * *$ & $0,019 * * *$ \\
\hline & & & $(0,006)$ & $(0,006)$ \\
\hline \multirow[t]{2}{*}{ Conta Própria } & - & - & $-0,008 * *$ & $-0,007 * *$ \\
\hline & & & $(0,004)$ & $(0,004)$ \\
\hline \multirow[t]{2}{*}{ Declarante } & - & - & $0,017 * * *$ & $0,019 * * *$ \\
\hline & & & $(0,003)$ & $(0,003)$ \\
\hline \multirow[t]{2}{*}{ Chefe } & - & - & 0,000 & 0,000 \\
\hline & & & $(0,003)$ & $(0,003)$ \\
\hline \multirow[t]{2}{*}{ Afazeres domésticos } & - & - & 0,000 & 0,000 \\
\hline & & & $(0,000)$ & $(0,000)$ \\
\hline \multirow[t]{2}{*}{ Norte } & - & - & - & $-0,070 * * *$ \\
\hline & & & & $(0,004)$ \\
\hline \multirow[t]{2}{*}{ Nordeste } & - & - & - & $-0,038 * * *$ \\
\hline & & & & $(0,004)$ \\
\hline \multirow[t]{2}{*}{ Sul } & - & - & - & $-0,035 * * *$ \\
\hline & & & & $(0,004)$ \\
\hline \multirow[t]{2}{*}{ Centro Oeste } & - & - & - & $-0,038 * * *$ \\
\hline & & & & $(0,004)$ \\
\hline
\end{tabular}

Nota: erro-padrão robusto entre parênteses. $* * *$ Denota significância ao nível de 1\%; ** Denota significância ao nível de 5\%, * Denota significância ao nível de $10 \%$.

Fonte: Elaboração própria a partir dos microdados da PNAD/IBGE (suplemento de saúde). 
Observa-se que para as mulheres, na Tabela 14, além da variável Educação ter mantido a significância estatística do Modelo 1 ao Modelo 4, o impacto do coeficiente também aumentou. Para os homens, como pode ser verificado na Tabela 15, o coeficiente da variável Educação também se manteve significativo do Modelo 1 ao Modelo 4, sendo que o impacto do coeficiente praticamente não se alterou.

\section{Considerações finais}

A percepção de boa saúde não promove apenas o bem-estar individual, mas permite, também, trabalhar regularmente, ser mais produtivo e trabalhar por mais anos. Os indivíduos saudáveis contribuem para a saúde da população de forma geral porque não propagam infecções e têm condições físicas e mentais para cuidar dos outros.

As mulheres se declararam menos saudáveis que os homens, porém, a expectativa de vida feminina é maior. Apesar das mulheres viverem mais que os homens, elas estão mais propensas a ter algum tipo de doença crônica, assim, elas vivem mais, só que em piores condições. Os homens estão mais propensos ao óbito por causas de mortes violentas, tais como homicídios e acidentes de trânsito ou devido às doenças de maior taxa de mortalidade, como doenças cardiovasculares. As mulheres que não praticam nenhum tipo de atividade doméstica em seus lares se declararam mais saudáveis que os homens nas mesmas condições. Contudo, no modelo econométrico, esta variável não apresentou significância estatística.

A educação apresentou impacto positivo sobre a saúde tanto dos homens como das mulheres, o que já era previsto pela revisão de literatura. Mas, a educação teve maior impacto sobre a saúde das mulheres. A incidência de pobreza não foi estatisticamente significativa para explicar a percepção de saúde das mulheres, contudo, para os homens, esta variável foi significativa, além de ser um dos fatores que mais contribuíram para queda na probabilidade dos homens se declararem saudáveis.

As regiões foram algumas das variáveis que mais contribuíram para a percepção de saúde de homens e mulheres. As regiões Norte, Nordeste, Centro Oeste e Sul apresentaram coeficiente negativo, isto significa que os indivíduos que residiam nestas regiões se declararam menos saudáveis que os indivíduos que residiam na região Sudeste. Esta diferença regional de percepção de saúde pode estar refletindo a desigualdade de acesso a serviços de saúde nestas regiões, assim como os aspectos sociais e econômicos dos seus residentes.

O sexo determina diferentes papéis, em média, as mulheres recebem menos por hora trabalhada, ocupam cargos com menos prestígio social, estão mais propensas a condições de trabalho precário e enfrentam dupla jornada de trabalho, portanto, as mulheres estão mais sujeitas ao desgaste físico e mental. Assim, os diferenciais em termos de saúde se devem em grande parte às desigualdades nas variáveis acima citadas, as quais deveriam ser o foco de ação, no sentido de redução desta desigualdade de gênero. 
Bruna Naiara de Castro, Jefferson Andronio Ramundo Staduto

\section{Referências bibliográficas}

ALVES, L. F.; ANDRADE, M. V. Impactos do estado de saúde sobre os rendimentos individuais no brasil e em minas gerais. Economia Aplicada, São Paulo, v. 7, p. 359-388, 2003.

ANDREWS, D. W. K.; MOREIRA, M. J.; H., S. J. Optimal two-sided invariant similar tests for instrumental variables regression. Econometrica, v. 74, p. 715-752, May 2006.

ARENDT, J. Does education cause better health? A panel data analysis using school reforms for identification. Economics of Education Review, v. 24, p. 149-160, 2005.

BARATA, R. B. Como e por que as desigualdades sociais fazem mal à saúde. 1. ed. Rio de Janeiro: Fiocruz, 2009.

BASOV, S. Heterogenous human capital: life cycle investment in health and education. Australia, 2002. p. 24.

BECKER, G. S. Investiment in human capital: a theoretical analysis. Journal of Political Economy, v. 70, n. 5, p. 9-49, Oct. 1962.

BECKER, G. S. Human capital revisited. In: BECKER, G. Human capital: a theoretical and empirical analysis with special reference to education. 3. ed. Chicago: The University of Chicago Press, 1994. p. 15-28.

BENJAMINS, M. et al. Self-reported health and adult mortality risk: an analysis of causespecific mortality. Social Science \& Medicine, p. 28, Oct. 2004.

BRASIL. Ministério da Saúde. $8^{a}$ Conferência Nacional de Saúde. Brasília: Ministério da Saúde, 1986. p. 29.

BRUNELLO, G. et al. The causal effect of education on health: what is the hole of health behaviors? Economics Series, Viena, v. 280, p. 32, Dec. 2011.

COSTA, R. R. F. O efeito da educação sobre estado de saúde individual no Brasil. 2008, $104 f$. Dissertação (Mestrado em Economia)-Centro de Desenvolvimento e Planejamento Regional da Faculdade de Ciências Econômicas da Universidade Federal de Minas Gerais, Belo Horizonte, 2008.

CRUZEIRO, C. M. P. F. S. D. R.; VERÍSSIMO, C. M. F. Auto percepção do estado de saúde nos países mediterrânicos da União Europeia em homens e mulheres. Coimbra: Escola Superior de Enfermagem de Coimbra, 2013. p. 2.

DACHS, J. N. W. Determinantes das desigualdades na auto-avaliação do estado de saúde no Brasil: análise dos dados da PNAD/1998. Ciência e Saúde Coletiva, v. 7, n. 4, p. 641-657, 2002 .

DIENER, E.; SCOLLOM, C. N.; LUCAS, R. E. The evolving concept of subjective well-being: the multifaceted nature of happiness. Cell Aging and Gerontology, v. 15, p. 187-219, 2003. 
DOYAL, L. Sex, gender, and health: the need for a new approach. British Medical Journal, v. 323, n. 3, p. 1061-1063, Nov. 2001.

FERNANDES, A. A. et al. Envelhecimento e saúde: uma análise de gênero. Lisboa: Faculdade de Ciências Sociais e Humanas, 2012. p. 86.

FERREIRA, P. L.; SANTANA, P. Percepção de estado de saúde e de qualidade de vida da população activa: contributo para a definição de normas portuguesas. Revista Portuguesa de Saúde Pública, v. 21, n. 2, p. 15-30, jun./dez 2003.

FINLAY, K.; MAGNUSSON, L. M. Implementing weak instrument robust tests for a general class of instrumental variables models. The Stata Journal, v. 9, n. 3, p. 1-26, Jan. 2009.

FISCHER, J. A. Subjective well-being as welfare measure: concepts and methodology. Munich Personal RePEc Archive, Paris, p. 43, Jul. 2009.

FUCHS, V. R. Reflections on the socio-economic correlates of health. Journal of Health Economics, Stanford, v. 23, p. 653-661, Aug. 2004.

GALINHA, I.; RIBEIRO, J. L. P. História e evolução do conceito de bem-estar subjetivo. Psicologia, Saúde \& Doenças, v. 6, n. 2, p. 203-214, 2005.

GIATTI, L.; BARRETO, S. M. Situação do indivíduo no mercado de trabalho e iniqüidade em saúde no Brasil. Revista Saúde Pública, Belo Horizonte, v. 1, n. 40, p. 99-106, 2006.

GORMAN, B. K.; READ, J. G. Gender disparities in adult health: an examination of three measures of morbidity. Journal of Health and Social Behavior, v. 47, n. 2, p. 95-110, Jun. 2006.

GREENE, W. C. Econometric analysis. 5. ed. New Jersey: Prentice Hall, 2002.

GROSSMAN, M. On the concept of health capital and the demand for health. The Journal of Political Economy, v. 80, n. 2, p. 223-255, Mar./Apr. 1972.

GROSSMAN, M. The human capital model. New York: Elsevier Science, 2000.

HOSSEINPOOR, A. R. et al. Social determinants of self-reported health in women and men: understanding the role of gender in opulation health. Plos One, v. 7, n. 4, Apr. 2012.

KASSOUF, A. L. Saúde e mercado de trabalho. Pesquisa e Planejamento Econômico, Rio de Janeiro, v. 27, n. 3, p. 587-610, dez. 1997.

KON, A. A economia política do gênero: determinantes da divisão do trabalho. Revista de Economia Política, v. 22, n. 3, p. 89-106, jul./set. 2002.

LEIGH, J. P. A. R. D. Schooling and frailty among seniors. Economics of Education Review, v. 16, n. 1, 1997. 
Bruna Naiara de Castro, Jefferson Andronio Ramundo Staduto

LLERAS-MUNEY, A.; LICHTENBERG, F. R. The effect of education on medicaltechnology adoption: are the more educated more likely to use new drugs? Princeton University, Abr. 2002. (Working Paper, n. 9185).

LUECHINGER, S. Valuing air quality using the life satisfaction approach. University of Zurich, Swiss Federal Institute of Technology. Zurich, 2007. p. 52.

MAIA, A. G.; RODRIGUES, C. G. Saúde e mercado de trabalho no Brasil: diferenciais entre ocupados agrícolas e não agrícolas. Revista de Economia e Sociologia Rural, Piracicaba, v. 48, n. 4, p. 737-765, out./dez. 2010.

MELO, H. P. D.; CONSIDERA, C. M.; SABBATO, A. D. Os afazeres domésticos contam. Niterói: Universidade Federal Fluminense, 2005. p. 1-24.

MENDES, J. D. V.; SALA, A. Perfil da morbidade das internações masculinas no Estado de São Paulo. Boletim Epidemiológico Paulista, v. 8, n. 93, p. 22-31, 2011.

MENDES, R. O impacto dos efeitos da ocupação sobre a saúde trabalhadores. Revista de Saúde Pública, São Paulo, v. 22, n. 4, p. 311-326, 1988.

MOREIRA, M. J. A conditional likelihood test for structural models. Econometrica, v. 71, n. 4, p. 1027-1048, 2003.

MURRUGARRA, E.; VALDIVIA, M. The returns to health for peruvian urban adults: differentials across genders the live-cycle and the wage distribution. Washington, D.C.: InterAmerican Development Bank, 1999. p. 47.

NERI, M.; SOARES, W.; SOARES, C. Condições de saúde no setor de transporte rodoviário de cargas e de passageiros: um estudo baseado na Pesquisa Nacional por Amostra de Domicílios. Caderno de Saúde Pública, Rio de Janeiro, v. 21, n. 4, p. 1107-1123, jul./ago. 2005.

PINDYCK, R. S.; RUBINFELD, D. L. Econometria. 4. ed. Rio de Janeiro: Elsevier, 2004.

PINHEIRO, R. S. et al. Gênero, morbidade, acesso e utilização de serviços de saúde no Brasil. Saúde Coletiva, v. 7, n. 4, p. 687-707, 2002.

PINHEIRO, T. F.; COUTO, M. T. Homens, masculinidades e saúde: uma reflexão de gênero na perspectiva histórica. Boletim do Instituto de Saúde, v. 14, p. 49-55, 2012.

PRUS, S. G.; GEE, E. Gender differences in the influence of economic, lifestyle, and psychosocial factors on later-life health. Canadian Journal of Public Health, v. 94, n. 4, p. 114, jul./ago. 2003.

ROSS, C. E.; WU, C. The links between education and health. American Sociological Review, v. 60, n. 5, p. 719-745., Oct. 1995. 
Percepção de saúde no Brasil: uma análise das diferenças por sexo dos trabalhadores

SACHSIDA, A.; MENDONÇA, M. J.; MEDRANO, L. A. Inflação, desemprego e choques cambiais: novas evidências para o Brasil. Brasilia: Ipea, ago. 2011. 39p. (Texto para Discussão, n. 1661).

SANDER, W. Schooling and smoking. Economics of Education Review, v. 14, n. 1, p. 23-33, Mar. 1995.

SCHULTZ, T. P. Human capital investment in women and men: micro and macro evidence of economic returns. San Francisco: An International Center for Economic Growth Publication, 1993.

SCHULTZ, T. W. Capital humano: investimentos em educação e pesquisa. Rio de Janeiro: Zahar Editores, 1973.

SCLIAR, M. História do conceito de saúde. Saúde Coletiva, Rio de Janeiro, v. 17, n. 1, p. 29 $41,2007$.

SILVA, L. M. V.; ALMEIDA-FILHO, N. Eqüidade em saúde: uma análise crítica de conceitos. Caderno de Saúde Pública, Rio de Janeiro, v. 2, p. 217-226, 2009.

SINGH, L. et al. Determinants of gender differences in self-rated health among older population: evidence from India. Sage Open, p. 1-12, Abr./Jun. 2013.

SOUSA, E. A. Efeitos da educação sobre a saúde do indivíduo: uma análise para a região nordeste do Brasil. 2010, 82f. Dissertação (Mestrado Economia Aplicada)-Programa de PósGráduação em Economia Aplicada da Faculdade de Economia, Administração e Contabilidade da Universidade Federal de Alagoas, Maceió, 2010.

SOYTAS, M. A.; KOSE, T. Gender differences in self-reported health status: cross-country evidence from Turkey and the united states. Job Market Paper, p. 1-30, Nov. 2014.

STIGLITZ, J. E.; SEN, A. F. J. P. Report by the commission on the measurement of economic performance and social progress. [S.n.t.], p. 292. 2009.

STOCK, J. H.; YOGO, M. Testing for weak ins truments in linear IV regression. In: ANDREWS, D. W.; STOCK, J. H. Identification and inference for econometric models: essays in honor of Thomas Rothenberg. Cambridge: Cambridge University Press, 2005. p. 80-108.

STOPA, S. R. et al. Acesso e uso de serviços de saúde pela população brasileira, Pesquisa Nacional de Saúde 2013. Rev Saúde Publica, v. 51, n. Supl 1:3s, p. 1-11, 2017.

STRAUSS, J. T. D. Health, nutrition, and economic development. Journal of Economic Literature, v. 36, n. 2, p. 766-817, Jun. 1998.

TRAVASSOS, C.; OLIVEIRA, E. X. G.; VIACAVA, F. Desigualdades geográficas e sociais no acesso aos serviços de saúde no Brasil: 1998 e 2003. Ciência \& Saúde Coletiva, v. 11, n. 2, p. 975-986, 2006. 
Bruna Naiara de Castro, Jefferson Andronio Ramundo Staduto

VINTÉM, J. M.; GUERREIRO, M. D. D.; CARVALHO, H. Desigualdades de género e sociais na saúde e doença em Portugal: uma análise do Módulo "Saúde" do European Social Survey-2004. Lisboa: Universidade Nova de Lisboa, 2008. p. 1-16.

WHO. Constitution of the world health organization. $45^{\mathrm{a}}$ ed. Genebra, 1946. p. 18.

WILKINSON, R.; MARMOT, M. Social deternimants of health: the solid facts. [S.n.t.], p. 135, 2003.

WOOLDRIGE, J. M. Introdução à econometria: uma abordagem moderna. 1. ed. São Paulo: Cengage Learning, 2008. 